reduced during the first six months by non-closure of the defect. Presumably non-closure allows cerebrospinal fluid to escape from the open neural tube, postponing the development of hydrocephalus until epithelium has formed. As deferred shunt operations are associated with a better prognosis, ${ }^{4}$ nonclosure may in fact be advantageous, delaying the onset of ventriculitis until the child is immunologically more competent.

Thus early closure has no advantage over non-closure with respect to mortality and the incidence of hydrocephalus and ventriculitis. Non-closure not only means that neonates are spared major operations but also reduces the number of shunt operations required in children who have a limited life expectancy. Knowing that non-closure is safe and potentially beneficial means that the family does not have to make an urgent and immediate choice between life and death on the birth of a baby with an open neural tube defect, ${ }^{5}$ allowing time for all concerned fully to assess the baby's condition.

1 Mawdsley T, Rickman PP. Further follow-up study of early operation for open myelomeningocele. Dev Med Child Neurol [Suppl] 1969;20:8-12.

2 Smyth BT, Piggot J, Forsythe WI, et al. A controlled trial of immediate and delayed closure of myelomeningocele. $\mathcal{F}$ Bone foint Surg [Br] 1974;56:297-304.

3 Boston $\mathrm{VE}$, Wilkinson $\mathrm{A}$. A retrospective analysis of conservative versus active management in severe open myelomeningocele. $Z$ Kinderchir 1979;28:340-7.

4 Hemmer R. Surgical treatment of hydrocephalus: complications, mortality, developmental prospects. $Z$ Kinderchir 1977;22:443-9.

5 Menzies RG, Parkin JM, Hey EN. Prognosis for babies with meningomyelocele and high lumbar paraplegia at birth. Lancet 1985;ii:993-5.

(Accepted 14 fanuary 1988)

Royal Belfast Hospital for Sick Children, Belfast BT12 6BE

G T DEANS, FRCS, surgical registrar

V E BOSTON, MD, FRCS, consultant paediatric surgeon

Correspondence and requests for reprints to: Mr Boston

\section{Nephrotic syndrome after treatment with 5-aminosalicylic acid}

Several new derivatives of sulphasalazine that make use of its active moiety, 5 -aminosalicylic acid, have recently been introduced for the treatment of inflammatory bowel disease. ${ }^{1}$ In rats short term intravenous administration of 5-aminosalicylic acid has been associated with nephrotoxicity. ${ }^{2}$ No cases of minimal change nephropathy have been reported with either sulphasalazine or 5-aminosalicylic acid in man. We describe a patient who developed a nephrotic lesion within five months after starting treatment with mesalazine (5-aminosalicylic acid coated with an acrylic based resin).

\section{Case report}

A 61 year old white woman with a 30 year history of ulcerative colitis was admitted because of the sudden onset of swelling of her face and fingers. Until five months before admission her colitis had been well controlled with occasional betamethasone retention enemas. Colonoscopy showed a severe colitis up to $30 \mathrm{~cm}$ from the anal margin; this responded to a short course of steroid enemas. Because she did not tolerate sulphasalazine she was started on mesalazine $800 \mathrm{mg}$ thrice daily.

Examination showed periorbital, ankle, and sacral oedema. Blood pressure was $120 / 70 \mathrm{~mm} \mathrm{Hg}$. Laboratory investigations showed a full blown nephrotic syndrome: serum albumin concentration $16 \mathrm{~g} / \mathrm{l}$ cholesterol concentration $11.3 \mathrm{mmol} / \mathrm{l}$, and proteinuria $28 \mathrm{~g} / 24 \mathrm{~h}$ ( $90 \%$ albumin as determined by urinary protein electrophoresis). Serum creatinine concentration was $141 \mu \mathrm{mol} / \mathrm{l}$, and urea concentration $13.3 \mathrm{mmol} / \mathrm{l}$. The urinary sediment was unremarkable. Biopsy of the duodenum and colon showed no amyloidosis. A percutaneous renal biopsy showed normal glomeruli with slight proliferation of the mesangium. Results of immunofluorescence were negative. Electron microscopy showed fusion of the foot processes but no other abnormality. Minimal change nephropathy was diagnosed.

Mesalazine was stopped and prednisone $1 \mathrm{mg} / \mathrm{kg} /$ day started. The nephrotic syndrome responded after six weeks of treatment. Prednisone was tapered off until being stopped after four months. The patient experienced a moderate flare up of her colitis three months after stopping prednisone, which again responded to steroid enemas. One year later her nephropathy was in complete remission.

\section{Comment}

5-Aminosalicylic acid is released in the large bowel on dissolution of the resin coating of mesalazine tablets. ${ }^{3}$ Though it has been shown to induce tubular and renal papillary necrosis, ${ }^{2}$ it has not been reported to cause minimal change nephropathy. Non-steroidal anti-inflammatory drugs, in particular the propionic class of these compounds, have been reported to cause acute interstitial renal failure with minimal change nephropathy. ${ }^{4}$ Although both these renal lesions are usually present, lipoid nephrosis has occurred as the sole lesion..$^{5}$ In this context 5 -aminosalicylic acid may be viewed as a non-steroidal anti-inflammatory agent.

After five months of treatment with mesalazine our patient developed a full blown nephrotic syndrome. Percutaneous renal biopsy showed the typical features of minimal change nephropathy. There was a temporal relation between treatment with mesalazine and the onset of the glomerulopathy, and withdrawal of the drug and prolonged treatment with corticosteroids resulted in complete remission of the nephropathy. We did not consider it ethical to rechallenge the patient with the drug. Although the nephropathy may have been coincidental or related to her basic illness, her nephrosis did not recur despite a relapse of the colitis. Given the strong temporal relation, we suggest that the glomerulopathy may have been caused by 5 -aminosalicylic acid in a manner similar to other non-steroidal antiinflammatory drugs.

1 Dew MJ, Cadwell M, Kidwai NS, Evans BK, Rhodes EJ. 5-Aminosalicylic acid in serum and urine after administration by enema to patients with colitis. I Pharm Pharmacology 1984;35:323-4. 2 Calder IC, Funder CC, Green CR, Ham KN, Tange JD. Nephrotoxic lesions from 5-aminosalicylic acid. BrMed f 1972;i:52-4.

3 Dew MJ, Ryder REJ, Evans N, Evans BK, Rhodes EJ. Colonic release of 5-aminosalicylic acid from an oral preparation in active ulcerative colitis. Br f Clin Pharmacol 1983;16:185-7.

4 Finkelstein A, Fraley DS, Stachura I, Feldman HA, Gandy DR, Bourke E. Fenoprofen nephropathy: lipoid nephrosis and interstitial nephritis. A possible T-lymphocyte disorder. Am f Med 1982;72:81-7.

5 Chatteriee GP. Nephrotic syndrome induced by tolmetin. FAMA 1981;246:1589.

(Accepted 9 December 1987)

Meir General Hospital, 44281 Kfar-Saba, Israel

B H NOVIS, MB, MRCP, head of gastroenterology unit

Z KORZETS, MB, BS, staff nephrologist

$P C H E N, M D$, registrar in medicine

J BERNHEIM, MD, head of nephrology unit

Correspondence to: Professor Novis.

\section{Firefighting and malignant hyperthermia}

The complication of anaesthesia malignant hyperthermia occurs in people who have an underlying disorder of the muscle membranes. Such people may also present with heat stroke $^{1}$ or with rhabdomyolysis induced by phenothiazine drugs or severe infections. ${ }^{2}$ We believe this is the first description of an occupational cause of rhabdomyolysis in someone known to be susceptible to malignant hyperthermia

\section{Case report}

In July 1985 the 43 year old father of a 12 year old girl who had survived an episode of malignant hyperthermia during a general anaesthesia was found to have a raised serum creatine kinase activity of $650 \mathrm{IU} / 1$ (normal range $10-200 \mathrm{IU} / \mathrm{l}$ ). In vitro testing of muscle with halothane and caffeine showed that he too was susceptible to malignant hyperthermia. At that time he was working as a computer salesman, but he subsequently got a job in a factory that made fire extinguishers. One of his tasks was to discharge bromochlorodifluoromethane from the extinguishers before refilling them. This work was usually done in the open air, but it was hard to avoid inhaling some of the gas. In March 1987 he consulted a physician (DGB), complaining of malaise and of stiffness and weakness in his forearms and hands during the 18 months that he had been in this job. The symptoms worsened during the working week, being worst on Fridays, and improved at weekends. Serum creatine kinase activity was $1056 \mathrm{IU} / 1$ on one Saturday in March 1987 and 544 IU/1 on the following Monday. Physical examination showed no abnormality.

Because of the structural similarity between bromochlorodifluoromethane and halothane (bromochlorotrifluoroethane) the effect of bromochlorodifluoromethane on muscle contraction in vitro was examined. Bromochlorodifluoromethane produced an effect identical with that of halothane in inducing contraction in muscle from both humans and swine susceptible to malignan hyperthermia. He was advised to change his job, which he did; his symptoms immediately improved.

\section{Comment}

The clinical and laboratory findings in this patient indicated that he had rhabdomyolysis due to recurrent exposure to bromochlorodifluoromethane. 